\title{
Reproductive outcomes following Hysteroscopic Removal of endometrial polyps of different location, number, and size in patients with infertility Ismaeel Mohammed Adb EL Azim Mira, Abdelmonsef Abdelhamed Sedek, Hazem Shaban Eldesoky
}

Department of Obstetrics and Gynecology, Faculty of Medicine - Al-Azhar University

Corresponding author: Hazem Shaban Eldesoky, Mobile: 01000434937;

Email: hzemshaman@gmail.com

\begin{abstract}
Background: hysteroscopic resection is a relatively safe and simple procedure which effectively removes polyps; however, endometrial polyps can recur. Studies have suggested recurrence rates of up to $46 \%$, and therefore it is important to identify risk factors associated with recurrence.

Objective: To assess the pregnancy rate after hysteroscopic polypectomy in infertility patients with endometrial polyps to compare pregnancy rate among subgroups with polyps of different locations, number and size.

Patients and Methods: These Prospective Cohort Study on 60 cases were conducted at the department of obstetrics \& gynecology Sayed Galal Univeraity hospital between May 2017 and april 2018. Patients with unexplained infertility. two groups.

Results: In our study we compare the pregnancy rate according to polyp characteristics such as location, size and number. also we study the reproductive outcome of hysteroscopy in two groups: 1st group without intrauterine lesion. 2 - 2nd group with endometrial polyps. and we found that: there is no statistically deference between the two groups the p-value is 0.40654 . We found a non significant positive correlations between Pregnancy outcome and number of polyps with p-value 0.71 , a non significant positive correlations between Pregnancy outcome and size of polyps with p-value 0.456 and a non significant negative correlations between Pregnancy outcome and site of polyps.

Conclusion: We found that there is no statistically deference between the two groups. We found a non significant positive correlations between Pregnancy outcome and number of polyps, , size of polyps and ,site of polyps
\end{abstract}

Keywords: infirtility, endometrial polyp, hysteroscopy

\section{INTRODUCTION}

Endometrial polyps are focal growths of the uterine mucosa and consist of endometrial glands, stroma and blood vessels. It is estimated that uterine polyps are found in $10 \%$ of general female population ${ }^{(1)}$ while they may be asymptomatic; polyps are commonly identified during investigations for abnormal uterine bleeding and infertility. abnormal uterine bleeding is the most common symptom of endometrial polyps, and in women with such bleeding, the prevalence of endometrial polyps is thought to be between 20 and $30 \%{ }^{(2,3)}$. In $80 \%$ of the cases, such polyps appear in an isolated form, although there also can be multiple polyps. In post-menopausal patients, the polyp glands are atrophic epithelial tissue and surrounded by fibrous stroma (4). Structural uterine abnormalities such as endometrial polyps, uterine fibroids, Mullerian abnormalities and intrauterine adhesions may interfere with this relationship and contribute to implantation failure, which has been considered to constitute a significant proportion of in vitro fertilisation (IVF) failures. Endometrial polyps are the commonest structural abnormalities of the uterine cavity, with prevalence varying between $7.8 \%$ and $34.9 \%{ }^{(5)}$. This frequency is even higher in fertile population and reported to be $32 \%$ in a large prospective trial ${ }^{(6)}$.

Prevalence of Endometrial Polyps in Infertile Women Since transvaginal ultrasound examination (TVUS) has become a standard part of the gynaecological assessment, and saline infusion sonography or hysteroscopy are often performed if intrauterine mass lesions are suspected, polyps are more frequently detected. This approach has led to an increase in the 
diagnosis of endometrial polyps in subfertile and otherwise asymptomatic patients. Polyps are considered amongst factors that might contribute to infertility and recurrent pregnancy loss. It has been postulated that congenital uterine anomalies and acquired structural cavitary defects such as leiomyomas, polyps and synechiae might have negative impact on endometrial receptivity and thus implantation failure. This presents a major clinical challenge and is a cause of considerable stress to patients. The prevalence of such unsuspected intrauterine abnormalities, diagnosed by hysteroscopy prior to IVF, has been described to be between 11 and $45 \%{ }^{(6,7)}$.

Scientific debate regarding the relationship between endometrial polyps and infertility continues since the effect of polyps on fertility is conflicting and there exists no evidence on the effectiveness of the hysteroscopic polypectomy in improving the prognosis in infertile women ${ }^{(8)}$. as considered on the basis that polyps may possibly have detrimental effects on fertility outcomes, Make a subtitle for ethical statements in the patients and methods section.

it seems plausible to assume that the size, number and the location of endometrial polyps could be significant confounders, however, there exist a limited number of studies in the literature that reported on the endometrial polyp location in the infertility population ${ }^{(9,10)}$.

hysteroscopy with guided biopsy is considered the gold standard for diagnosing endometrial polyps (II). hysteroscopy also facilitates assessment of size, number, and vascular characteristics of endometrial polyps ${ }^{(12)}$. Prior to the routine use of hysteroscopy, blind dilation and curettage were used for the diagnosis of endometrial polyps ${ }^{(13)}$. This technique, however, caused polyp fragmentation making histopathologic diagnosis difficult ${ }^{(14)}$.

hysteroscopic resection is a relatively safe and simple procedure which effectively removes polyps; however, endometrial polyps can recur. Studies have suggested recurrence rates of up to $46 \%$, and therefore it is important to attempt to identify risk factors associated with recurrence ${ }^{(15)}$.
The small diameter of the hysteroscope coupled with the ease of working with the instruments inserted through the working channel and the ability to work with a continuous flow have made it possible that we can currently combine the operative part with the diagnostic part, thus avoiding the risks that a surgical procedure entails for the patient ${ }^{(16)}$.

\begin{abstract}
AIM OF THE WORK
to assess the pregnancy rate after hysteroscopic polypectomy in infertility patients with endometrial polyps, to compare pregnancy rate among subgroups with polyps of different location, number and size.
\end{abstract}

\section{PATIENTS AND METHODS}

This prospective cohort study on sixty cases were conducted at the department of obstetrics \& gynecology sayed galal univeraity hospital between May 2017 and April 2018 on patients with unexplained infertility, Written informed consent was obtained.

hysteroscopy performed to patients with unexplained infertility; the study group was composed of sixty women in two groups according to inclusion and exclusion criteria and we will compare the pregnancy rate between two groups, the 1st group without intrauterine lesion while the 2nd group with endometrial polyps.

Patients with intrauterine lesions other than endometrial polyp must be excluded; Patients with endometrial polyps must be evaluated and compare the pregnancy rate according to polyp characteristics such as location, size and number. Patients evaluated according to polyp location in five subgroups corpus anterior, corpus posterior, lateral, uterotubal and multiple polyp number in two subgroups single and multiple, polyp size in three subgroups $<1 \mathrm{~cm}, 1-1.9 \mathrm{~cm}$ and $\geq 2 \mathrm{~cm}$

Inclusion criteria: Age: 20-35 years old. Primary infirtility: failure of conception for at least 12 months despite of normal sexual life without use of contraceptives. Good results of folliculometry by TVUS. normal hormonal profile including normal basal level of FSh, Lh, progesterone, TSh 
and prolactin. normal semen analysis. patient fallopian tubes by hSG.

Exclusion criteria: patient received hormonal treatment during the last 3 months. Women's ages $>35 y s \&<20 y s$, other causes of infertility such as: Tubal pathology as hydrosalpinx \& pyosalpinx, male infertility. presence of any diagnosed endocrinopathy such as: D.M. cushing Syndrome. hypo- or hyper-thyroidism. hyperprolactinemia, BMI $<17.9$, or $>35$.

Operative hysteroscopy in operating room under Anesthesia: polypectomy was done by means of semirigid $5 \mathrm{~mm}$ continous flow operative hysteroscope based on $2.9 * \mathrm{~mm} 30$ degree lens system with a $5 \mathrm{Fr}$ working channel: Size of inner sheath $4.3 \mathrm{~mm}$. Size of outer sheath $5 \mathrm{~mm}$ (BETTOcchI hystroscope $5 \mathrm{~mm}$ ). the endometrial polyp was rsected by Biplor resectoscope and the resected tissue is submitted for pathological study.

The patient was placed in the dorsal lithotomy position. The thighs should be at a 90 degree angle to the pelvis in order to create enough space for the surgeon to manipulate the hysteroscope. The perineum should be just past the edge of the table. A vaginal disinfection with a non-irritating disinfection solution (povidone iodine 10\% solution) was performed without placing speculum.

The tip of the hysteroscope was positioned in the vaginal introitus, the labia being slightly separated with fingers. Normal saline was used for uterine distension connected to the inflow channel on the sheath with intravenous tubing. The scope was driven to the posterior fornix to readily visualize the portion and slowly backwards to identify the external cervical, finally the evaluation and the data that had been found were written in details by the surgeon Any complication in the form of pain, bleeding, vasovagal attack and perforation, were registered in the patient sheet.

Follow-up of the patients after hysteroscopy for 6 months and detect whether conception had occurred or not.

\section{Ethical statements}

Written informed consent was obtained. hysteroscopy were performed to 120 patients with unexplained infertility. The study was approved by the Ethics Board of Al-Azhar University.

\section{Statistical Analysis}

Data will be collected, revised, coded and entered to the Statistical Package for Social Science (IBM SPSS) version 23 and the following was done:

Qualitative data were presented as number and percentages while quantitative data were presented as mean, standard deviations and ranges.

The comparison between two independent groups with quantitative data and parametric distribution was done by using Independent t-test. Pearson correlation coefficients will be used to assess the relation between two studied parameters in the same group. The confidence interval was set to $95 \%$ and the margin of error accepted was set to $5 \%$. So, the $p$-value was considered significant as the following: $\mathrm{P}>0.05$ : non significant. $\mathrm{P}<0.05$ : Significant. $\mathrm{P}<0.01$ : highly significant.

\section{Results}

Table (1): Comparison between frequency of positive and negative pregnancy test among group with endometrial polyps and group without intrauterine lesion

\begin{tabular}{|l|c|c|c|c|c|}
\hline \multirow{2}{*}{} & \multicolumn{2}{|c|}{ Group with EP } & \multicolumn{2}{c|}{ Group without EP } & \multirow{2}{*}{ P value } \\
\cline { 2 - 5 } & Percent & Frequency & Percent & Frequency & \multirow{2}{*}{$\mathrm{P}=0.406$} \\
\hline Negative & $63.3 \%$ & 19 & $73.3 \%$ & 22 & 8 \\
\hline Positive & $36.7 \%$ & 11 & $26.7 \%$ & & \\
\hline
\end{tabular}

p-value is not significant at $\mathrm{p}$-value $>0.05$.

There is nonsignificant defernce in pregnancy outcome between the two groups. 
Table (2): Frequency of Positive and Negative Pregnancy Test according to polyp position, number of polyps and size of polyps

\begin{tabular}{|l|c|c|c|c|c|}
\hline \multicolumn{2}{|c|}{} & \multicolumn{4}{c|}{ BHCG Test } \\
\cline { 3 - 6 } \multicolumn{2}{c|}{} & \multicolumn{2}{c|}{ Negative } & \multicolumn{2}{c|}{ Positive } \\
\cline { 3 - 6 } & & Percent & Number & Percent & Number \\
\hline \multirow{3}{*}{$\begin{array}{l}\text { Position of } \\
\text { Polyps }\end{array}$} & Uterotubal & $10 \%$ & 3 & $6.7 \%$ & 2 \\
\cline { 2 - 6 } & Corpus anterior & $13.3 \%$ & 4 & $6.7 \%$ & 2 \\
\cline { 2 - 6 } & Corpus posterior & $16.7 \%$ & 5 & $10 \%$ & 3 \\
\cline { 2 - 6 } & Multiple & $13.3 \%$ & 4 & $10 \%$ & 3 \\
\cline { 2 - 6 } No of polyps & Lateral & $10 \%$ & 3 & $3.3 \%$ & 1 \\
\cline { 2 - 6 } & Single & $50 \%$ & 15 & $26.7 \%$ & 8 \\
\hline \multirow{3}{*}{ Size of Polyps } & Multiple & $13.3 \%$ & 4 & $10 \%$ & 3 \\
\cline { 2 - 6 } & $\mathbf{< 1} \mathrm{cm}^{\mathbf{3}}$ & $23.3 \%$ & 7 & $10 \%$ & 3 \\
\cline { 2 - 6 } & $\mathbf{1 - 1 . 9 \mathrm { cm } ^ { \mathbf { 3 } }}$ & $30 \%$ & 9 & $16.7 \%$ & 5 \\
\hline
\end{tabular}

The most frequent positive cases were cases suffered from corpus posterior polyps and polyps with multiple positions while the less frequent positive cases were cases with lateral position polyps. The most frequent positive cases according to number of polyp are cases suffered from single polyp. The most frequent positive cases according to size of polyp are cases suffered from polyp of size $1-1.9 \mathrm{~cm}^{3}$.

Table (3): Correlations between no of polyps, size of polyps, position of polyps and pregnancy outcome among patient group with endometrial polyps

\begin{tabular}{|c|c|c|c|c|c|}
\hline & & $\begin{array}{c}\text { BHCG } \\
\text { Test }\end{array}$ & No of polyps & Size of Polyps & $\begin{array}{c}\text { Position of } \\
\text { Polyps }\end{array}$ \\
\hline \multirow{3}{*}{ BHCG Test } & Pearson Correlation & 1 & .071 & .141 & .034 \\
\hline & $\mathrm{P}$ value & & .710 & .456 & .857 \\
\hline & $\mathrm{N}$ & 30 & 30 & 30 & 30 \\
\hline \multirow{3}{*}{$\begin{array}{l}\text { No of } \\
\text { polyps }\end{array}$} & Pearson Correlation & .071 & 1 & .212 & $.446^{*}$ \\
\hline & Sig. (2-tailed) & .710 & & .260 & .013 \\
\hline & $\mathrm{N}$ & 30 & 30 & 30 & 30 \\
\hline \multirow{3}{*}{$\begin{array}{l}\text { Size of } \\
\text { Polyps }\end{array}$} & \begin{tabular}{|l|} 
Pearson \\
Correlation \\
\end{tabular} & .141 & .212 & 1 & .114 \\
\hline & \begin{tabular}{|l|} 
Sig. (2-tailed) \\
\end{tabular} & .456 & .260 & & .549 \\
\hline & $\mathrm{N}$ & 30 & 30 & 30 & 30 \\
\hline \multirow{3}{*}{ Position of Polyps } & Pearson Correlation & .034 & $.446^{*}$ & $-.114-$ & 1 \\
\hline & Sig. (2-tailed) & .857 & .013 & .549 & \\
\hline & $\mathrm{N}$ & 30 & 30 & 30 & 30 \\
\hline
\end{tabular}

*. Correlation is significant at the 0.05 level (2-tailed). There is significant correlation between position of polyps and the number of polyps with p-value 0.013 while there is no any other correlation between the three cases (number of polyps, size of polyps and position of polyps), also there is no significant correlation between the pregnancy outcome with the three cases 
Table (4): Pregnancy outcome after hystroscopy according to Number,site and size of of endometrial polyps.

\begin{tabular}{|c|c|c|c|c|c|}
\hline & Negative & Positive & R Square & chi-square & p-value \\
\hline Single polyp & 15 & 8 & \multirow{2}{*}{.005} & \multirow{2}{*}{0.1507} & \multirow{2}{*}{0.654} \\
\hline Multiple polyps & 4 & 3 & & & \\
\hline Uterotubal position & 3 & 2 & \multirow{5}{*}{.001} & \multirow{5}{*}{0.1507} & \multirow{5}{*}{0.824} \\
\hline Corpus anterior position & 4 & 2 & & & \\
\hline Corpus posterior position & 5 & 3 & & & \\
\hline Multiple positions & 4 & 3 & & & \\
\hline Lateral position & 3 & 1 & & & \\
\hline Size of polyp $<1 \mathrm{~cm}^{3}$ & 7 & 3 & \multirow{3}{*}{.020} & \multirow{3}{*}{0.6562} & \multirow{3}{*}{0.7203} \\
\hline Size of polyp $=1-1.9 \mathrm{~cm}^{3}$ & 9 & 5 & & & \\
\hline Size of polyp $\geq 2 \mathrm{~cm}^{3}$ & 3 & 3 & & & \\
\hline
\end{tabular}

There no significant outcome after operation related to polyp number, site or size.

Table (5): Correlations between patient age, body mass index, duration of infertility and pregnancy outcome among patient group without intrauterine lesion

\begin{tabular}{|c|c|c|c|c|c|}
\hline & & Body mass index & $\begin{array}{c}\text { Duration of } \\
\text { infertility }\end{array}$ & Age & BHCG \\
\hline \multirow{3}{*}{ Body mass index } & Pearson Correlation & 1 & $.791 * *$ & $.887 * *$ & 0.249 \\
\hline & Sig. (2-tailed) & & .000 & .000 & .184 \\
\hline & $\mathrm{N}$ & 30 & 30 & 30 & 30 \\
\hline \multirow{3}{*}{$\begin{array}{l}\text { Duration of } \\
\text { infertility }\end{array}$} & $\begin{array}{l}\text { Pearson } \\
\text { Correlation }\end{array}$ & $.791 * *$ & 1 & $.931 * *$ & $-.384-*$ \\
\hline & Sig. (2-tailed) & .000 & & .000 & .036 \\
\hline & $\mathrm{N}$ & 30 & 30 & 30 & 30 \\
\hline \multirow{3}{*}{ Age } & $\begin{array}{l}\text { Pearson } \\
\text { Correlation }\end{array}$ & $.887 * *$ & $.931 * *$ & 1 & $-.327-$ \\
\hline & Sig. (2-tailed) & .000 & .000 & & .078 \\
\hline & $\mathrm{N}$ & 30 & 30 & 30 & 30 \\
\hline \multirow{3}{*}{ BHCG } & Pearson Correlation & 0.249 & $-.384-*$ & $-.327-$ & 1 \\
\hline & Sig. (2-tailed) & .184 & .036 & .078 & \\
\hline & $\mathrm{N}$ & 30 & 30 & 30 & 30 \\
\hline
\end{tabular}

**. Correlation is significant at the 0.01 level (2-tailed).

*. Correlation is significant at the 0.05 level (2-tailed).

Negative correlation between pregnancy outcome and duration of infertility reflects decrease of pregnancy chance when the duration period of infertility increases among patient group without intrauterine lesion. significant correlation between Body mass index and duration of infertility and age and significant correlation between age and Duration of infertility. 
Table (6): Correlations between patient age, body mass index, duration of infertility and pregnancy outcome among patient group with endometrial polyps

\begin{tabular}{|l|l|c|c|c|c|}
\hline \multicolumn{2}{|c|}{} & $\begin{array}{c}\text { BHCG } \\
\text { Test }\end{array}$ & $\begin{array}{c}\text { Duration of } \\
\text { infertility }\end{array}$ & Patient age & $\begin{array}{c}\text { Body Mass } \\
\text { Index }\end{array}$ \\
\hline \multirow{3}{*}{ BHCG Test } & Pearson Correlation & 1 & .305 & .353 & .189 \\
\cline { 2 - 6 } & Sig. (2-tailed) & & .101 & .055 & .317 \\
\cline { 2 - 6 } & $\mathrm{N}$ & 30 & 30 & 30 & 30 \\
\hline \multirow{2}{*}{$\begin{array}{l}\text { Duration of } \\
\text { infertility }\end{array}$} & Pearson Correlation & .305 & 1 & $.891^{* *}$ & $.453^{*}$ \\
\cline { 2 - 6 } & Sig. (2-tailed) & .101 & & .000 & .012 \\
\cline { 2 - 6 } & $\mathrm{N}$ & 30 & 30 & 30 & 30 \\
\hline \multirow{3}{*}{ Patient age } & Pearson Correlation & .353 & $.891^{* *}$ & 1 & $.467^{* *}$ \\
\cline { 2 - 6 } & Sig. (2-tailed) & .055 & .000 & & .009 \\
\cline { 2 - 6 } & $\mathrm{N}$ & 30 & 30 & 30 & 30 \\
\hline \multirow{2}{*}{$\begin{array}{l}\text { Body Mass } \\
\text { Index }\end{array}$} & Pearson Correlation & .189 & $.453^{*}$ & $.467^{* *}$ & 1 \\
\cline { 2 - 6 } & Sig. (2-tailed) & .317 & .012 & .009 & \\
\cline { 2 - 6 } & $\mathrm{N}$ & 30 & 30 & 30 & 30 \\
\hline
\end{tabular}

**. Correlation is significant at the 0.01 level (2-tailed). *. Correlation is significant at the 0.05 level (2-tailed). Non significant correlation between pregnancy outcome and patient age, body mass index or duration of among patient group with endometrial polyps.significant correlation between body mass index and duration of infertility and age and significant correlation between age and duration of infertility.

\section{DISCUSSION}

Although endometrial polyps are commonly encountered pathologies among subfertile women robust evidence for their effect on fecundity and pregnancy outcome is lacking.many noncontrolled studies suggest inconsistent results concerning the effectiveness of hysteroscopic polypectomy ${ }^{(17,18)}$.

The size and the number of the endometrial polyps are the other possible confounders of the fertility outcomes. Isikoglu et al. ${ }^{(19)}$ concluded in their retrospective study that polyps less than $1.5 \mathrm{~cm}$ do not require treatment before ICSI as they do not appear to have any negative effects on pregnancy and implantation rates. Lass ${ }^{(20)}$ reported that polyps under $2 \mathrm{~cm}$ did not decrease clinical pregnancy and live birth rates however they may increase the risk of miscarriages. Wang and Mendel ${ }^{(21)}$ also reported similar results. Conversely, Shokeir et al. ${ }^{(9)}$ concluded that functional endometrial polyps, even if small, are likely to impair fertility and removal of these lesions may improve subsequent reproductive performance.
Stamatellos and Whitworth ${ }^{(22)}$ demonstrated that hysteroscopic polypectomy improved the rate of spontaneous conception regardless size or number of the polyps. also, pregnancy or miscarriage rates were not different between women who underwent polypectomy for a small polyp $(\leq 1 \mathrm{~cm})$ and those who had surgery for bigger or multiple polyps. another study by Preutthipan and herabutya (23) revealed that there was no significant difference in reproductive outcome between patients having polyps $\leq 2.5 \mathrm{~cm}$ and $>$ $2.5 \mathrm{~cm}$. Karakus et al. (24) examine fertility outcomes among patients with polyps $<1 \mathrm{~cm}, 1-$ $1.9 \mathrm{~cm}$ and $\geq 2 \mathrm{~cm}$, the results were not significantly differ $(p=0.600)$. Additionally, patients with 2 or 3 polyps had a greater chance of conceiving after polypectomy than those with a single polyp, even though the difference was not statistically significant $(p=0.065)$.

however, Karakus et al. ${ }^{(24)}$ study differs from the one by Yanaihara et al. ${ }^{(10)}$ from the point that both biochemical and clinical pregnancy rates are provided separately, Karakus et al. ${ }^{(24)}$ Examined the impact of the varying sizes and numbers, in 
addition to location, of polyp on the reproductive outcomes. Based on the results of the present study, we suggest that, in infertil patients, frequency of hysteroscopic polypectomy is $23.3 \%$ and most polyps are solitary $76.7 \%$ however it was $2.1 \%$ and $97.9 \%$ in Karakus et al. ${ }^{(24)}$ Study.

The highest polyp location site is uterine corpus posterior was $27.6 \%$ followed by multiple sites $23.3 \%$. the most common size was $1-1.9 \mathrm{~cm}$ $(46.7 \%)$. There appears no difference regarding reproductive outcomes after hysteroscopic resection of polyps situated in different intrauterine locations ${ }^{(24)}$. similarly in our results the chance of conceiving seems not to change after hysteroscopic treatment of polyps of different size and number.however, studies regarding the relationship between polyp location and fertility outcomes are considerably insufficient and there are no studies in the literature that provide live birth rates. a properly designed, adequately powered RCT that takes into account the cumulative live birth rate following hysteroscopic treatment of endometrial polyps at different locations is needed.

In our study we compare the reproductive outcome of hysteroscopy among the two groups: 1st group without intrauterine lesion, 2nd group with endometrial polyps. also we study the pregnancy rate according to polyp characteristics such as location, size and number. and we found that: there is no statistically deference between the two groups the p-value is 0.40654 as I reported in table (1).

We examined the correlations between patient age, body mass index, duration of infertility and pregnancy outcome among patient group without intrauterine lesion and we found a Negative correlation between pregnancy outcome and duration of infertility reflects decrease of pregnancy chance when the duration period of infertility increases among patient group without intrauterine lesion. significant correlation between Body mass index and duration of infertility and age and significant correlation between age and Duration of infertility as I reported in table (5). We examined the correlations between patient age, body mass index, and Pregnancy outcome among patient group with endometrial polyps; non significant correlation between pregnancy outcome and patient age, body mass index or duration of among patient group with endometrial polyps.significant correlation between body mass index and duration of infertility and age and significant correlation between age and duration of infertility.our results in age as I reported in table (6), Body Mass Index agree with. as they are well known risk factors for the development of endometrial polyps ${ }^{(25,26)}$. of these risk factors, age is perhaps the most wellknown risk factor. The prevalence of endometrial polyps increases with age, though it is unclear whether this trend continues past menopause. We examined the correlations between pregnancy outcome, and position, size and the number of polyps among patient group with endometrial polyps; significant correlation between position of polyps and the number of polyps with p-value 0.013 while there is no any other correlation between the three cases (number of polyps, size of polyps and position of polyps), also there is no significant correlation between the pregnancy outcome with the three cases I reported in table (3). We examined the pregnancy outcome after hystroscopy according to Number,site and size of of endometrial polyps and we found that There no 
significant outcome after operation related to polyp number, site or size. The most frequent positive cases were cases suffered from corpus posterior polyps and polyps with multiple positions while the less frequent positive cases were cases with lateral position polyps. The most frequent positive cases according to number of polyp are cases suffered from single polyp. The most frequent positive cases according to size of polyp are cases suffered from polyp of size $1-1.9 \mathrm{~cm}^{3}$ as I reported in table (2).

\section{CONCLUSION}

We found that there is no statistically deference between the two groups. We found a non significant positive correlations between Pregnancy outcome and number of polyps, a non significant positive correlations between Pregnancy outcome and size of polyps and a non significant negative correlations between Pregnancy outcome and site of polyps.

\section{REFERENCES}

1. Ledger W, Clark J (2014): Recent Advances in Obstetrics Gynaecology: JP Medical Ltd.

2. Bakour S, Gupta J, Khan K (2002): Risk factors associated with endometrial polyps in abnormal uterine bleeding. International Journal of Gynecology Obstetrics, 76 (2): 165-168.

3. Elfayomy AK, Habib FA, Alkabalawy MA (2012): Role of hysteroscopy in the detection of endometrial pathologies in women presenting with postmenopausal bleeding and thickened endometrium. Archives of gynecology and obstetrics, 285 (3): 839-843.
4. Antunes A, Costa-Paiva L, Arthuso M, Costa J, Pinto-Neto A (2007): Endometrial polyps in pre-and postmenopausal women: factors associated with malignancy. Maturitas, 57 (4): 415-421.

5. Anastasiadis PZ, Reynolds AB (2000): The p120 catenin family: complex roles in adhesion signaling and cancer. J Cell Sci., 113 (8): 13191334.

6. Hinckley MD, Milki AA (2004): 1000 officebased hysteroscopies prior to in vitro fertilization: feasibility and findings. JSLS: Journal of the Society of Laparoendoscopic Surgeons, 8 (2): 103

7. Makrakis E, Hassiakos D, Stathis D, Vaxevanoglou T, Orfanoudaki E, Pantos K (2009): Hysteroscopy in women with implantation failures after in vitro fertilization: findings and effect on subsequent pregnancy rates. Journal of minimally invasive gynecology, 16(2):181-7.

8. Bosteels J, Kasius J, Weyers S, Broekmans FJ, Mol BWJ, D'Hooghe TM (2015): Hysteroscopy for treating subfertility associated with suspected major uterine cavity abnormalities. Cochrane Database of Systematic Reviews, (2): 1523.

9. Shokeir T, Shalan H, El-Shafei M (2004): Significanceof endometrial polyps detected hysteroscopically in eu-menorrheic infertile women. J Obstet Gynaecol Res., 30 (2): 83-84

10. Yanaihara A, Yorimitsu T, Motoyama H, Iwasaki S, Kawamura T (2008): Location of endometrial polyp and pregnancy rate in infertility patients. Fertility and sterility, 90 (1): 180-182.

11. Bettocchi S, Ceci O, Nappi L, Di Venere R, Masciopinto V, Pansini V Cormio G (2004): Operative office hysteroscopy without anesthesia: analysis of 4863 cases performed with mechanical instruments. The Journal of the American Association of Gynecologic Laparoscopists, 11 (1): 59-61. 
12. https://www.researchgate.net/.../313619755_ The_value_of_hysteroscopic_biopsy_in_th....

13. Gimpelson RJ, Rappold HO (1988): A comparative study between panoramic hysteroscopy with directed biopsies and dilatation and curettage: a review of 276 cases. American journal of obstetrics and gynecology, 158 (3): 489492.

14. Svirsky R, Smorgick N, Rozowski U, Sagiv R, Feingold M, Halperin R, Pansky M (2008): Can we rely on blind endometrial biopsy for detection of focal intrauterine pathology? American journal of obstetrics and gynecology, 199 (2): 113-115.

15. Gu P, Zhang S, Li X, Wang $X$, Wen $T$, Jehan $R$ Wang $X$ (2018): Recent advances in layered double hydroxide-based nanomaterials for the removal of radionuclides from aqueous solution. Environmental pollution, 240: 493-505.

16. Wortman M, Daggett A, Ball C (2013): Operative hysteroscopy in an office-based surgical setting: review of patient safety and satisfaction in 414 cases. Journal of minimally invasive gynecology, 20 (1): 56-63

17. Spiewankiewicz B, Stelmachow J, Sawicki W, Cendrowski K, Wypych P, Swiderska K (2003): The effectiveness of hysteroscopic polypectomy in cases of female infertility. Clinical and experimental obstetrics \& gynecology, 30 (1): 23-25.

18. Batioglu S, Kaymak O (2005): Does hysteroscopic polypectomy without cycle cancellation affect IVF? Reproductive biomedicine online, 10 (6): 767-769.
19. Isikoglu $M$, Berkkanoglu $M$, Senturk $Z$, Coetzee K, Ozgur K (2006): Endometrial polyps smaller than $1.5 \mathrm{~cm}$ do not affect ICSI outcome. Reproductive biomedicine online, 12 (2): 199-204.

20. Lass A (1999): The fertility potential of women with a single ovary. Human reproduction update, 5 (5): 546-550.

21. Wang LX, Mendel JM (1992): Generating fuzzy rules by learning from examples. IEEE Transactions on systems man and cybernetics, 22 (6): 1414-1427.

22. Stamatellos D, Whitworth AP (2008): The properties of brown dwarfs and low-mass hydrogen-burning stars formed by disc fragmentation. Monthly Notices of the Royal Astronomical Society, 392 (1): 413-427.

23. Preutthipan S, Herabutya Y (2005): Hysteroscopic polypectomy in 240 premenopausal and postmenopausal women. Fertility and sterility, 83 (3): 705-709.

24. Karakus T, Baydas O, Gunay F, Coban M, Goktas Y (2016): Orchestrating learning during implementation of a 3D virtual world. New Review of Hypermedia and Multimedia, 22 (4): 303-320.

25. Onalan R, Onalan G, Tonguc E, Ozdener T, Dogan M, Mollamahmutoglu L (2009): Body mass index is an independent risk factor for the development of endometrial polyps in patients undergoing in vitro fertilization. Fertility and sterility, 91 (4): 1056-1060.

26. Nappi RE, Lachowsky M (2009): Menopause and sexuality: prevalence of symptoms and impact on quality of life. Maturitas, 63 (2): 138-141. 